\title{
PREDICTION OF MECHANICAL PROPERTIES - MODULUS OF RUPTURE AND MODULUS OF ELASTICITY - OF FIVE TROPICAL SPECIES BY NONDESTRUCTIVE METHODS
}

\author{
Jan Baar ${ }^{1, \wedge}$, Jan Tippner ${ }^{1}$, Peter Rademacher ${ }^{1}$
}

\begin{abstract}
This paper analyzes the usability of different dynamic moduli of elasticity and wood density for the prediction of mechanical properties - static modulus of elasticity and modulus of rupture - in samples with grain deflection from the longitudinal direction. Five tropical hardwoods (Afzelia bipindensis, Intsia bijuga, Millettia laurentii, Astronium graveolens and Microberlinia brazzavillensis) with different grain characteristics were used for this purpose. The fiber deflection was caused by the presence of interlocked grain or the working process. The three nondestructive techniques used in this study - longitudinal and flexural resonance method and ultrasound method - provided higher values of modulus of elasticity than the static bending test, but close correlation was observed between these variables. The weakest correlation was found for the ultrasound method which is probably caused by its measuring mechanism. The prediction of the modulus of rupture is less accurate when the dynamic modulus of elasticity is compared with the static modulus of elasticity; on the other hand, it was still good in comparison with the density model, which is inapplicable when grain deflection occurs in wood. In the wood of Zebrano where the interlocked grain was strongly developed, almost all of the correlation coefficients showed the lowest values and the prediction of modulus of rupture by nondestructive techniques was unsatisfactory.
\end{abstract}

Keywords: Density, dynamic modulus of elasticity, interlocked grain, modulus of rupture, nondestructive methods, tropical wood.

\section{INTRODUCTION}

Nondestructive evaluation of wood mechanical properties has a long history of use on different objects ranging from standing trees to wood-based composites (Mattheck and Bethge 1993; Kasal and Anthony 2004; Ross et al. 2004, Liu et al. 2006). The acoustic techniques are considered among various nondestructive methods as the best option for the prediction of wood stiffness without modifying its enduse. These methods apply a close correlation between the dynamic and the static modulus of elasticity values which was proved for sound wood in different states such as timber (Hassan et al. 2013), logs (Zhou et al. 2013) or Laminated Veneer Lumber (Wang et al. 2003) and decayed wood as well (Yang et al. 2003). Few studies deal with different tropical species such as Sextonia rubra for which nondestructive methods were used for predicting the stiffness of lumber with very high accuracy $(\mathrm{r}=0,91$ for stress wave method) (Teles et al. 2011). Karlinasari et al. (2008) showed a strong relation between the static and the ultrasound dynamic moduli of elasticity for small clear specimens of four tropical hardwoods $(\mathrm{r}=0,82)$, on the other hand, lower values were found when species were evaluated individually.

In some wood applications, such as structural evaluation of lumber, a reliably specified strength is a fundamental need. The underlying principle of common machine stress grading of lumber is that the bending stiffness of timber is closely correlated to its strength (Schajer 2001, Oja et al. 2005). This close positive correlation has been shown in many works (Bodig and Jayne 1982, Karlinasari et al. 2005,

\footnotetext{
' Mendel University in Brno, Faculty of Forestry and Wood Technology, Department of Wood Science, Zemědělská 3, Brno, 61300, Czech Republic.

^Corresponding author: jan.baar@mendelu.cz

Received: 05.01.2014 Accepted. 18.06. 2014
} 
Ravenshorst et al. 2008, Hein and Lima 2012). Ravenshorst et al. (2008) used a method based on the fundamental frequency for strength grading of ten tropical hardwoods for which the dynamic modulus of elasticity was strongly correlated with the static modulus of elasticity $(r=0,85)$ and the bending strength $(\mathrm{r}=0,82)$. The method was used consistently for all the tropical hardwoods, which are all used commonly in construction.

Mechanical properties have often been predicted from wood density, which was considered the most reliable and the simplest index of the wood strength (Tsoumis 1991). Izekor et al. (2010) showed very tight correlation for wood of plantation grown Tectona grandis characterized by the correlation coefficient 0,97 . A strong correlation between these two properties $(r=0,68 ; 0,89)$ is also reported for different Eucalyptus species by Hein et al. (2013) and Yang and Evans (2003). There is an approximately positive linear correlation between these two variables but the density influence is often weakened by the natural growth features like knots, cross grains, etc., occurring in wood. Therefore, the usability of density for the wood strength prediction is often limited only to clear straight-grained wood which does not correspond with the practice.

A great number of tropical species are typically found with a grain deviation described as interlocked grain (Cabrolier et al. 2009). Kribs (1950) stated that $75 \%$ of 258 evaluated tropical species showed this particular wood structure. Due to the highly anisotropic nature of wood, the actual orientation of grain inside a piece of wood strongly affects its apparent mechanical properties (Bodig and Jayne 1982). Weddell (1961) reported that the modulus of rupture (MOR) and the modulus of elasticity (MOE) in bending were negatively affected by the presence of interlocked grain in Entandrophragma utile and Ocotea rodiaei woods. Species used in this work are characterized by Chudnoff (1980) as follows: Astronium and Millettia species are primarily straight-grained, the grain in Intsia and Afzelia species can vary from straight to interlocked and Microberlinia wood is characterized by interlocked grain. Five tropical hardwoods with different grain direction were chosen for the purpose of this study. The fiber deflection from the longitudinal direction was given by occurrence of interlocked grain or by working process. The aim of this work was to find out if the dynamic modulus of elasticity is suitable for prediction of the wood mechanical properties (stiffness and strength) with grain deflection or interlocked grain. The ability of wood density to predict mechanical properties was evaluated as well.

\section{MATERIAL AND METHODS}

\section{Material}

Density, modulus of rupture in bending $(M O R)$, static modulus of elasticity in bending (MOE), longitudinal dynamic modulus of elasticity $\left(E_{l r}\right.$ and $\left.E_{u}\right)$ and flexural dynamic modulus of elasticity $\left(E_{l r}\right)$ were determined for the heartwood of five tropical hardwoods: Doussié (Afzelia bipindensis), Merbau (Intsia bijuga), Wengé (Millettia laurentii De Wild.), Muiracatiara (Astronium graveolens Jacq.) and Zebrano (Microberlinia brazzavillensis).

The sampled material was collected from a floor trading company and represents the tropical species commonly available at the European market. The species were identified on the basis of macroscopic and microscopic features. The dimensions of the samples were $60 \mathrm{~mm} \times 20 \mathrm{~mm}$ in cross section and 300 mm longitudinally. 30 samples of each species were used for the experiment. Samples were not carefully selected to correspond with requirements of standard so anatomical directions were not identical with the edges of the board. The growth rings were oriented randomly on cross section of the samples. The typical grain direction of samples from the species Merbau, Muiracatiara and Wengé was straight-grained, with fiber deflection up to 15 degrees in the longitudinal direction. In Merbau the characteristic grain pattern - interlocked grain - was limited to five samples. All Zebrano and Doussié samples were characterized by interlocked grain but the extent of the pattern was lower in Doussié. The grain angle on the sample surface ranged from 10 to 30 degrees for Doussié and 20 to 40 degrees for Zebrano. 
The samples were stored in the conditions of the experimental environment $(60 \%$ relative humidity at $20^{\circ} \mathrm{C}$ ) for 2 months until the moisture content of the samples stabilized at about $8 \%$ (the mean value determined by the gravimetric method). The density of samples was established based on their dimensions and weight measured at this moisture content.

\section{Methods}

Dynamic modulus of elasticity

Two methods for sound propagation velocity determination were used - the frequency-resonance method and the ultrasound method.

\section{The longitudinal resonance method}

Each sample $(60 \times 20 \times 300 \mathrm{~mm})$ was supported by two very soft foam prisms (free-free support condition). The longitudinal vibration of samples was induced by hitting a hammer on the sample front. The resulting vibrations were detected by a miniature piezoelectric one-axis accelerometer (MMF type KS94B.10, weight $3,5 \mathrm{~g}$, sensitivity $0,971 \mathrm{mV} \cdot \mathrm{m}^{-1} \cdot \mathrm{s}^{2}$ ) mounted on the other side. The natural frequency $f(\mathrm{~Hz})$ of the sample in the longitudinal direction, necessary for the stress-wave speed calculation, was examined by means of fast Fourier transform analysis (FFT) of time-domain signal in software Dewesoft version 6.6. The dynamic modulus of elasticity $\left(E_{l r}\right)$ was calculated using the following formula:

$$
E_{l r}=4 \rho f^{2} L^{2}
$$

where $\rho$ is the sample density, $f$ is the natural frequency of longitudinal vibration and $L$ is the length of sample.

\section{The flexural resonance method}

The points of support were located in the nodes of the fundamental mode of vibration $(22 \%$ of the sample length from each end $-0,224$ and 0,776 of the length). The same accelerometer was placed on the top of the sample near one end. The flexural vibration was induced by an impact to the center of the sample from above. The frequency of the fundamental mode of flexural vibration $\left(1^{\text {st }}\right.$ bending natural frequency) was used to count the dynamic modulus of elasticity $\left(E_{f r}\right)$ using equation:

$$
E_{f r}=0,947 \rho f^{2} L^{4} h^{-2},
$$

where $\rho$ is the sample density, $f$ is the natural frequency, $L$ is the length of the sample and $h$ is the thickness of the sample.

\section{The ultrasound method}

The ultrasound propagation time was measured by means of Fakopp Ultrasound Timer with two special triangle-shaped piezoelectric sensors type TD45 (working at a frequency of $45 \mathrm{~Hz}$ ). A short ultrasound impulse is generated by the electronic excitation of one transducer and received by the other one. The transit time of sound appears on the equipment display in microseconds. The time correction was carried out in compliance with the equipment producer's recommendation. The sensors are located on the side of the sample (on the same plane). The propagation time and the distance between sensors were used for the calculation of sound velocity along fibers according to the equation:

$$
c_{u}=L / t
$$

where $c_{u}$ is the velocity of ultrasound propagation $(\mathrm{m} / \mathrm{s}), \mathrm{t}$ is the propagation time $(\mathrm{s})$, and $L$ is the distance between sensors $(\mathrm{m})$. Dynamic modulus of elasticity $\left(E_{u}\right)$ is then calculated using equation: 


$$
E u=\rho c_{u}^{2},
$$

where $c_{u}$ is the calculated velocity (formula 3 ) and $\rho$ is the sample density.

\section{Static bending test}

Two samples of $20 \mathrm{~mm} \times 20 \mathrm{~mm}$ (cross section) $\times 300 \mathrm{~mm}$ were cut from each of the 30 originally tested boards. The static bending test was performed by the three-point loading method by the universal testing machine Zwick Z050 (loading capacity of $50 \mathrm{kN}$ ), the experiment procedure and evaluation of results was derived from BS 373 (British Standard Institution 1957). Each sample was tested in the same position as it was situated in the original board and it was loaded until destruction occurred to determine both the modulus of rupture (MOR) and the modulus of elasticity $(M O E)$. The span of supports was 240 $\mathrm{mm}$, the radius of supports and the forcing head was $15 \mathrm{~mm}$. The value of $M O R$ was calculated from the maximum loading force as it is given in equation:

$$
M O R=3 F_{\max } l / 2 b h^{2},
$$

where $F_{\max }$ is maximum loading force, $l$ is the span of supports, $b$ is the width of cross-section of sample and $h$ is thickness of the sample (height of cross-section).

The calculation of MOE was based on the forces measured at $10 \%$ and $40 \%$ of the maximum loading force (force of destruction) and the corresponding deflections of the bent beam were measured by extensometer. The $M O E$ was calculated using the equation:

$$
M O E=l^{3}\left(F_{40 \%}-F_{10 \%}\right) / 4 b h^{3}\left(u_{40 \%}-u_{10 \%}\right) \text {, }
$$

where $l$ is the span of supports, $F_{40 \%}$ and $F_{10 \%}$ are forces at the $40 \%$ and $10 \%$ level of the maximum force $F_{\max }, b$ is the width of the cross-section of sample and $h$ is thickness of the sample (height of crosssection), $u_{40 \%}$ and $u_{10 \%}$ are deflections at forces $F_{40 \%}$ and $F_{10 \%}$. The values of MOE and MOR calculated from the two measured specimens from each board were averaged.

\section{RESULTS AND DISCUSSION}

\section{Comparison of individual techniques}

The mean values of the static and the dynamic moduli of elasticity for individual species are summarized in table 1 for each of the four methods used. The analysis of variance (ANOVA) for individual species was conducted to compare the influence of measuring method on the dynamic modulus of elasticity. The ANOVA was significant $(\alpha=0,05)$, both within species and when individuals of all species were pooled together. Comparison (Tukey's HSD) indicated that the moduli values from the ultrasound method were significantly different from the values obtained from all the other methods in every case. The results obtained from the longitudinal resonance method was not significantly different from the flexural resonance method for wood of Wengé $(p=0,26)$ and Doussié $(p=0,24)$ and the static modulus of elasticity from the flexural resonance method for Doussié $(p=0,13)$ only. 
Table 1. Static and dynamic moduli of elasticity, modulus of rupture $(M O R)$ and wood density values for each species.

\begin{tabular}{crrrrrrr}
\hline & & $\begin{array}{c}\mathrm{MOE} \\
(\mathrm{GPa})\end{array}$ & $\begin{array}{c}\mathrm{E}_{\mathrm{fr}} \\
(\mathrm{GPa})\end{array}$ & $\begin{array}{c}\mathrm{E}_{\mathrm{lr}} \\
(\mathrm{GPa})\end{array}$ & $\begin{array}{c}\mathrm{E}_{\mathrm{u}} \\
(\mathrm{GPa})\end{array}$ & $\begin{array}{c}\text { MOR } \\
(\mathrm{MPa})\end{array}$ & $\begin{array}{r}\text { Density } \\
\left(\mathrm{kg} / \mathrm{m}^{3}\right)\end{array}$ \\
\hline Doussié & mean & 10,58 & 11,82 & 12,86 & 15,35 & 110,46 & 766,3 \\
& $\mathrm{CV}(\%)$ & 15,81 & 17,54 & 18,21 & 14,81 & 20,59 & 6,2 \\
\hline Merbau & mean & 15,04 & 16,48 & 18,22 & 20,52 & 152,51 & 812,9 \\
& $\mathrm{CV}(\%)$ & 11,13 & 11,37 & 13,42 & 10,65 & 13,82 & 9,1 \\
\hline Muiracatiara & mean & 14,29 & 16,10 & 17,92 & 19,79 & 138,05 & 839,5 \\
& $\mathrm{CV}(\%)$ & 16,15 & 11,84 & 11,88 & 10,24 & 21,90 & 10,1 \\
\hline \multirow{2}{*}{ Wengé } & mean & 13,61 & 15,38 & 16,57 & 18,51 & 130,69 & 855,9 \\
& $\mathrm{CV}(\%)$ & 16,13 & 16,03 & 15,01 & 14,79 & 23,58 & 10,2 \\
\hline Zebrano & mean & 15,19 & 17,57 & 19,62 & 22,72 & 133,28 & 809,8 \\
& $\mathrm{CV}(\%)$ & 14,15 & 13,90 & 14,62 & 14,42 & 25,9 & 6,6 \\
\hline
\end{tabular}

$\mathrm{CV}$ - coefficient of variation, $\mathrm{MOE}$ - static method, $\mathrm{E}_{\mathrm{fr}}-$ flexural resonance method; $\mathrm{E}_{\mathrm{lr}}-$ longitudinal resonance method, $\mathrm{E}_{\mathrm{u}}-$ ultrasound method.

The individual methods for the determination of the dynamic modulus of elasticity provided dissimilar values and the order from low to high was $\mathrm{E}_{\mathrm{fr}}<\mathrm{E}_{\mathrm{lr}}<\mathrm{E}_{\mathrm{u}}$. In this study, the values of the flexural resonance method are the nearest to the static bending test and exceed the static modulus of elasticity by $9,8 \sim 18,4 \%$. The mean value of modulus acquired from the longitudinal resonance method is higher than the value measured by the flexural resonance method and they differ from the static bending test by 31,5 and $20,6 \%$, respectively. The highest mean values of the modulus of elasticity for these five species were obtained by the ultrasound method and were 37,0 48,5\% higher than those acquired by the static bending test.

These findings are similar to results of other authors. Cho (2007) reported percentage differences of 16,4 and $25,2 \%$ between the static test and the resonance methods, respectively, for Camphor wood. Lower differences between methods were found by Haines et al. (1996) for spruce and fir, where the dynamic modulus established by the flexural resonance was $0,4 \%$ and $2,3 \%$ higher and the dynamic modulus established by the longitudinal ultrasound method was $17 \%$ and $22 \%$ higher than Young's modulus acquired by the static bending test. These lower values are caused by the use of the four-point bending test in the study (Haines et al. 1996). The three-point bending test provided the modulus of elasticity which is underestimated in relation to the four-point bending test due to its neglect of shear and indentation effects. This underestimation was valued by Brancheriau et al. (2002) to be about 19\%. Other researchers stated not only for hardwood species that the dynamic modulus of elasticity shows higher values than those measured by the static bending test (Bodig and Jayne 1982, Ilic 2001, Oliveira et al. 2002, Karlinasari et al. 2008). These differences are usually attributed to the viscoelastic behavior of wood (Haines et al. 1996, Cho 2007).

Divós and Tanaka (2005) showed that creep is not a phenomenon related only to long-term loading of wood, but the effect of creep can manifest in short time scales as well. The loading time in the case of the resonance method ranges between $0,1 \mathrm{~ms}$ and $1 \mathrm{~ms}$ depending on the vibration mode in comparison to the static bending test when the loading is distinctively longer - around $1 \mathrm{~min}$. Individual methods work with different typical durations of measurement and there is an inclination to get a higher MOE with shorter time which is analogical to results of Kolsky (1963), who predicted higher velocities of longitudinal waves at higher frequencies. 


\section{Prediction of static MOE by dynamic modulus of elasticity}

All samples of the observed species were combined to study the correlations between the nondestructive measurements and the bending stiffness in compliance with the standardized laboratory static method. The correlation between the individual dynamic moduli and the modulus of elasticity from the static bending test is shown in figure 1 and the correlation coefficients are presented in table 2. The closest-fitting relationship was found between the static and the flexural resonance methods, which is expressed by a correlation coefficient of 0,87 . Slightly lower coefficients were obtained by the longitudinal resonance and the ultrasound methods $-0,86$ and 0,83 , respectively, which still indicate that high predictability with the static values. Individual species analyses showed similar results when comparable coefficients were found for both the resonance methods and a distinctively less accurate prediction was provided by the ultrasound method (Table 2). Only in the case of Zebrano wood, where the interlocked grain was the most distinct, the values of the correlation coefficient were lower (Table 2) and the ultrasound method showed the highest correlation coefficient. The correlation analysis proved a suitability of these methods for predictions of the MOE with a higher precision degree for resonance methods. A very close relationship was observed between the two resonance methods which are based on a different mode of vibration and its fundamental frequency. The correlation coefficient was 0,99 , which indicates an interchangeability of both methods, with the exception of higher values of the longitudinal resonance method (by 7,9 11,3\%).
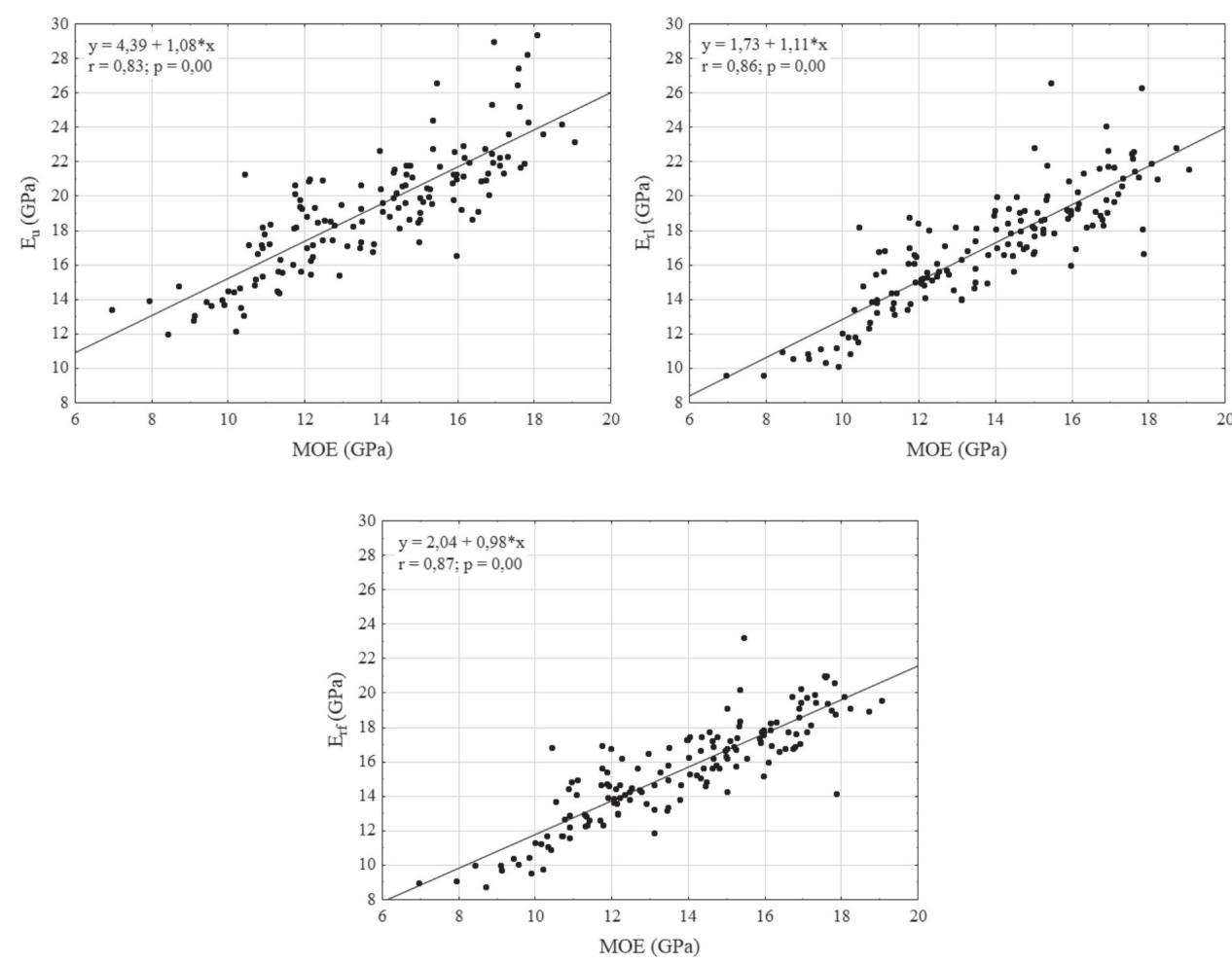

Figure 1. The correlation between three dynamic moduli of elasticity $\left(\mathrm{E}_{\mathrm{fr}}-\right.$ flexural resonance method; $\mathrm{E}_{\mathrm{lr}}$ - longitudinal resonance method, $\mathrm{E}_{\mathrm{u}}$ - ultrasound method) and the static modulus of elasticity (MOE) for all tested species.

In general, the results of other authors pointed out that nondestructive methods based on wave propagation are suitable for measurement of the dynamic modulus of elasticity and have a good relationship with the destructive static bending test. The strength of correlation is dependent on the species and the method used (Karlinasari et al. 2008, Ravenshorst et al. 2008, Teles et al. 2011). 
The results presented above show that nondestructive techniques are able to predict stiffness of wood with fiber deflection but the presence of interlocked grain can reduce the accuracy in some species. However, methods based on the ultrasound propagation are less suitable for the prediction of the MOE in comparison with the resonance method. Despite lower accuracy, the ultrasound methods are preferred for other benefits such as easier performance and potential use for in-situ measurements.

Table 2. Pearson correlation coefficients ( $r$ ) for relationships between variables (MOE - static method, $\mathrm{E}_{\mathrm{fr}}-$ flexural resonance method; $\mathrm{E}_{\mathrm{lr}}-$ longitudinal resonance method, $\mathrm{E}_{\mathrm{u}}-$ ultrasound method and $\mathrm{MOR}$ - modulus of rapture).

\begin{tabular}{|c|c|c|c|c|c|c|}
\hline $\begin{array}{l}\text { All } \\
\text { species\Doussié }\end{array}$ & MOE & $\mathrm{E}_{\mathrm{fr}}$ & $\mathrm{E}_{\mathrm{lr}}$ & $\mathrm{E}_{\mathrm{u}}$ & MOR & Density \\
\hline $\mathrm{MOE}$ & - & $0,96^{*}$ & $0,94^{*}$ & $0,80^{*}$ & $0,78^{*}$ & $0,06^{\text {n.s. }}$ \\
\hline $\mathrm{E}_{\mathrm{fr}}$ & $0,87^{*}$ & - & $0,99^{*}$ & $0,86^{*}$ & $0,76^{*}$ & - \\
\hline $\mathrm{E}_{\mathrm{lr}}$ & $0,86^{*}$ & $0,98^{*}$ & - & $0,86^{*}$ & $0,73^{*}$ & - \\
\hline $\mathrm{E}_{\mathrm{u}}$ & $0,83^{*}$ & $0,91^{*}$ & $0,92^{*}$ & - & $0,55^{*}$ & - \\
\hline MOR & $0,73^{*}$ & $0,56^{*}$ & $0,54^{*}$ & $0,49^{*}$ & 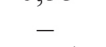 & $0,16^{\text {n.s. }}$ \\
\hline Density & $0,48^{*}$ & - & - & - & $0,33^{*}$ & - \\
\hline $\begin{array}{l}\text { Merbau } \backslash \text { Muiracati } \\
\text { ara }\end{array}$ & MOE & $\mathrm{E}_{\mathrm{fr}}$ & $\mathrm{E}_{\mathrm{lr}}$ & $\mathrm{E}_{\mathrm{u}}$ & MOR & Density \\
\hline $\mathrm{MOE}$ & - & $0,82^{*}$ & $0,85^{*}$ & $0,78^{*}$ & $0,86^{*}$ & $0,59^{*}$ \\
\hline $\mathrm{E}_{\mathrm{fr}}$ & $0,86^{*}$ & - & $0,98^{*}$ & $0,89^{*}$ & $0,58^{*}$ & - \\
\hline$E_{l r}$ & $0,85^{*}$ & $0,97^{*}$ & - & $0,90^{*}$ & $0,62^{*}$ & - \\
\hline \multirow[t]{2}{*}{$\mathrm{E}_{\mathrm{u}}$} & $0,68^{*}$ & $0,80^{*}$ & $0,84^{*}$ & - & $0,57^{*}$ & - \\
\hline & & & & 0,27 & & $0,41^{*}$ \\
\hline MOR & $0,68^{*}$ & $0,52^{*}$ & $0,54^{*}$ & n.s. & - & \\
\hline Density & $0,45^{*}$ & - & - & - & $0,38^{*}$ & - \\
\hline ZebranolWengé & $\mathrm{MOE}$ & $\overline{E_{\mathrm{fr}}}$ & $\mathrm{E}_{\mathrm{lr}}$ & $\overline{E_{u}}$ & MOR & Density \\
\hline $\mathrm{MOE}$ & - & $0,92^{*}$ & $0,90^{*}$ & $0,63^{*}$ & $0,67^{*}$ & $0,76^{*}$ \\
\hline $\mathrm{E}_{\mathrm{fr}}$ & $0,52^{*}$ & - & $0,99^{*}$ & $0,91^{*}$ & $0,62^{*}$ & - \\
\hline$E_{l r}$ & $0,48^{*}$ & $0,94^{*}$ & - & $0,93^{*}$ & $0,60^{*}$ & - \\
\hline \multirow[t]{2}{*}{$E_{u}$} & $0,60^{*}$ & $0,84^{*}$ & $0,80^{*}$ & - & $0,49^{*}$ & - \\
\hline & & 0,17 & 0,12 & 0,22 & & $0,33^{\text {n.s. }}$ \\
\hline MOR & $0,59^{*}$ & n.s. & n.s. & n.s. & - & \\
\hline Density & $0,51^{*}$ & - & - & - & $0,44^{*}$ & - \\
\hline
\end{tabular}

\section{Prediction of MOR by dynamic and static moduli of elasticity}

Generally the MOE is considered the most important strength predictor parameter. To gauge the relationship between different moduli of elasticity and the MOR, correlation and regression analyses were performed. Coefficients of correlation are shown in table 2 and the relationship between the modulus from the static bending test and the MOR for all samples is shown in figure 2. 


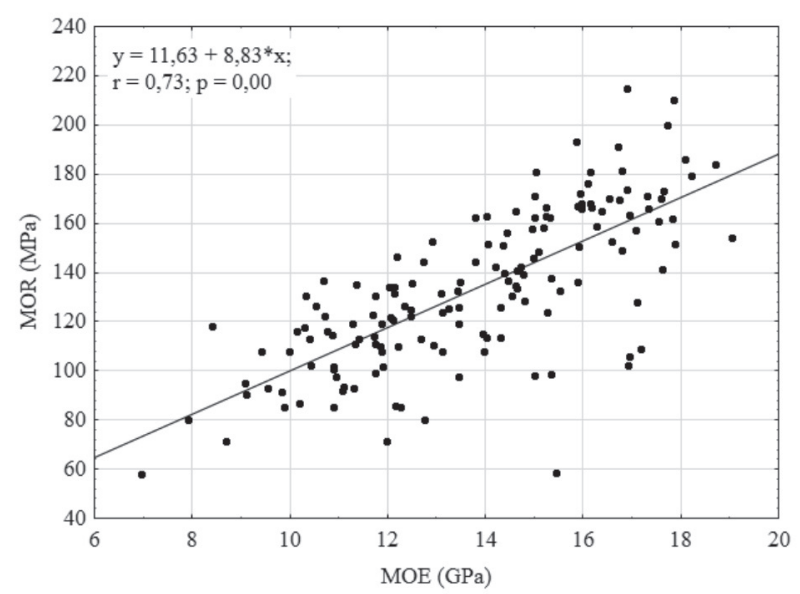

Figure 2. The correlation between static modulus of elasticity (MOE) and modulus of rupture (MOR) for all tested species.

The strongest relation was found between the static MOE and the MOR between species as well as within species. The correlation coefficients ranged between 0,59 and 0,86 . The lowest correlation coefficient for the static MOE from all the observed species was obtained for Zebrano wood $(r=0,59)$, probably because of the presence of interlocked grain. Similar correlation coefficients, ranging from 0,46 to 0,87 , were found by Karlinasari et al. (2005) for four tropical hardwoods and when all four species were evaluated together the correlation increased $(r=0,95)$.

The correlation between MOR and all the dynamic techniques was not found in our experiment for Zebrano wood, in which the grain was distinctively interlocked. The weakest prediction of the MOR was found in the case of the ultrasound method, where the correlation coefficients were $0,22 \sim 0,57$. Oliveira et al. (2002) described the relation between the ultrasound dynamic modulus and the MOR for two tropical species, Jatoba and Cupiúba, by linear regression with the coefficients of determination equal to 0,55 and 0,36 , respectively. The lower accuracy of the ultrasound method as concerns the prediction of wood mechanical properties is probably caused by its measuring mechanism. In the resonance method, the wave velocity, the main parameter determining the dynamic modulus of elasticity, is calculated on the basis of a much higher number of waves passing through the material and the entire section of the sample is involved. Contrary to this the ultrasound method determines the velocity based on the passage of one wave in a limited area connecting two measuring sensors (Grabianowski 2003, Hansen 2006). Therefore, it reflects the properties in that part of the sample only. Still, there was a medium to strong linear correlation between various moduli of elasticity and the MOR in all species except Zebrano where the interlocked grain is distinctively observed. Linear models relating the MOR and the static (MOE) and the dynamic flexural test $\mathrm{E}_{\mathrm{fr}}$ were constructed (Table 3). As can be observed, the static modulus of elasticity can explain the variability of the MOR better than the dynamic modulus of elasticity. 
Table 3. Regression equations of linear models to explain the relation of MOE vs. MOR and $\mathrm{E}_{\mathrm{fr}}$ vs. MOR for individual species.

\begin{tabular}{|c|c|c|c|c|}
\hline $\begin{array}{l}\text { Parameters } \\
\text { (x vs. y) }\end{array}$ & Species & $\begin{array}{c}\text { Linear regression } \\
\text { model }\end{array}$ & $r^{2}$ & $\begin{array}{l}\text { Significance } \\
(\alpha=0,05)\end{array}$ \\
\hline \multirow[t]{6}{*}{$\begin{array}{l}\text { MOE vs. } \\
\text { MOR }\end{array}$} & Doussié & $\begin{array}{l}y=-2,37+ \\
10,66 * x\end{array}$ & 0,615 & 0 \\
\hline & Merbau & $\begin{array}{l}y=23,38+ \\
8,59 * x\end{array}$ & 0,465 & 0 \\
\hline & Muiracatiara & $\begin{array}{l}y=-23,68+ \\
11,32 * x\end{array}$ & 0,746 & 0 \\
\hline & Wengé & $y=1,80+9,47 * x$ & 0,444 & 0 \\
\hline & Zebrano & $\begin{array}{l}y=-11,37+ \\
0,01 * x\end{array}$ & 0,351 & 0,0006 \\
\hline & All & $\begin{array}{l}y=11,63+ \\
8,83 * x\end{array}$ & 0,539 & 0 \\
\hline \multirow[t]{6}{*}{$E_{\mathrm{fr}}$ vs. MOR } & Doussié & $\begin{array}{l}y=12,94+ \\
8,29 * x\end{array}$ & 0,576 & 0 \\
\hline & Merbau & $\begin{array}{l}y=55,43+ \\
5,89 * x\end{array}$ & 0,274 & 0,0030 \\
\hline & Muiracatiara & $\begin{array}{l}y=-10,42+ \\
9,22 * x\end{array}$ & 0,338 & 0,0007 \\
\hline & Wengé & $y=9,75+7,86^{*} x$ & 0,384 & 0,0003 \\
\hline & Zebrano & $y=89,93+0 * x$ & 0,030 & 0,3564 \\
\hline & All & $\begin{array}{l}y=40,07+ \\
6,01 * x\end{array}$ & 0,312 & 0 \\
\hline
\end{tabular}

\section{Prediction of mechanical properties by density}

Wood density is considered by many authors (Zobel and Van Buijtenen 1989, Walker 1993) to be the most important wood property determining the mechanical properties of wood. In dense wood, there are more material distributed internal stresses, so the mechanical properties of wood increase as well. In our study the correlation coefficients obtained for the individual species were quite low and ranged from 0,16 (Doussié) to 0,44 (Zebrano) for MOR and from 0,06 (Doussié) to 0,76 (Wengé) for MOE (Table 2). When all species were considered together, the correlation coefficients were 0,33 and 0,48 for MOR and MOE, respectively. Linear models describing the relationship between density and MOR were characterized by very low coefficients of determination and most of them are not statistically significant. More significant relationships between density and wood strength were found by other authors (Izekor et al. 2010, Hein et al. 2013, Yang and Evans 2003). Density is the simplest index of strength, but only of wood without defects. There is an approximately linear relationship between strength and specific gravity in wood. However, wood of many tropical species includes growth anomalies like spiral or interlocked grain (Kribs 1950, Harris 1989). The fiber deflection from the longitudinal direction, which is connected with these defects, considerably influences wood stiffness and strength because of its anisotropic behaviour (Bodig and Jayne 1982, Tsoumis 1991). As seen in Table 2 and 3, the density is a poor predictor of wood strength when fiber deflection occurs in wood samples in comparison with the static or even the dynamic moduli of elasticity. 


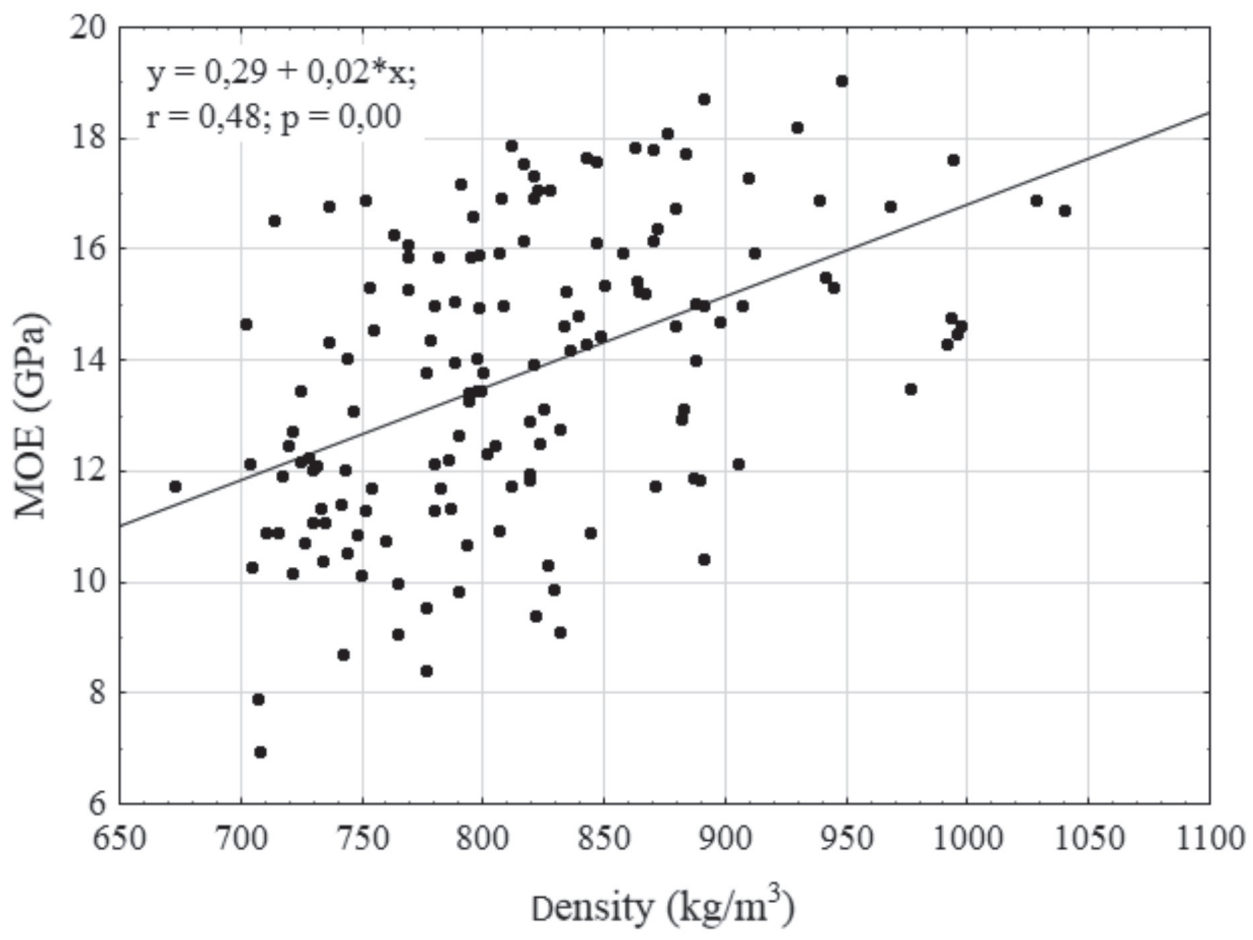

Figure 3. The correlation between wood density and static modulus of elasticity for all tested species.

Despite the common results that show density is a poor indicator of cell wall or wood stiffness (Cave and Walker 1994, Walker and Butterfield 1996), in our study it is better correlated with wood stiffness than with wood strength (Table 2 and Figure 3). Oja et al. (2005) attributed this to the fact that wood strength is to a large extent driven by local properties (e.g. large knot), while wood stiffness is more of an integrated effect of every part of the board. 


\section{CONCLUSIONS}

The samples of five tropical species with grain defects were tested by non-destructive methods based on wave propagation and the possibility of wood stiffness and strength prediction were analyzed.

The results show that the dynamic modulus of elasticity values obtained by the ultrasound, as well as the flexural and the longitudinal resonance methods are closely correlated with the static modulus of elasticity. A lower predictive accuracy of static modulus of elasticity was observed when the ultrasound technique was used. The values of the dynamic modulus of elasticity were always higher than the values obtained by the static bending test due to the viscoelastic behaviour of wood. The order from low to high was $\mathrm{MOE}<\mathrm{E}_{\mathrm{fr}}<\mathrm{E}_{\mathrm{lr}}<\mathrm{E}_{\mathrm{u}}$. All methods used were found to be suitable to assess the stiffness of wood

with grain deflection.

These methods were found to be less suitable in comparison with static MOE for prediction of wood strength (MOR). Similar positive correlations were found between MOR and both resonance methods and correlation coefficients ranged from 0,12 to 0,76 dependent on species. The ultrasound method showed again the weakest correlation to MOR. The correlation was not found for Zebrano in which distinct interlocked grain with high fiber deflection occurred.

A weak correlation was found between the density and the MOR $(r=0,16 \sim 0,44)$, which means that the density is a poor predictor of this property when grain deviation occurs in wood. In most species, the MOR was more closely correlated with the dynamic modulus of elasticity than with wood density except for Zebrano, where the correlation coefficients were very low for the dynamic modulus of elasticity. The distinctive grain deflection in all samples caused by the interlocked grain is the most likely source of this difference.

\section{ACKNOWLEDGMENT}

The paper was supported by the European Social Fund and the state budget of the Czech Republic, project "The Establishment of an International Research Team for the Development of New Wood-based Materials" reg. no. CZ.1.07/2.3.00/20.0269. Authors would also like to thank the producer of wooden floors MAGNUM Parket a.s. for the supply of materials used in the experiment. 


\section{REFERENCES}

Bodig, J.; Jayne, B.A. 1982. Mechanics of wood and wood composites. Van Nostrand Reinhold, New York.

Brancheriau, L.; Bailleres, H.; Guitard, D. 2002. Comparison between modulus of elasticity values calculated using 3 and 4 point bending tests on wooden samples. Wood Science and Technology 36:367-383.

BS 373. 1957. Methods of testing small clear specimens of timber. British Standard Institution, London.

Cabrolier, P.; Beauchêne, J.; Thibaut, B. 2009. Is interlocked grain an adaptive trait for tropical tree species in rainforest? In: Proceedings of the $6^{\text {th }}$ Plant Biomechanics Conference. Cayenne, French Guyana.

Cave, I.D.; Walker, J.C.F. 1994. Stiffness of wood in fast-grown plantation softwoods: the influence of microfibril angle. Forest Products Journal 44:43-48.

Cho, C.L. 2007. Comparison of three methods for determining Young's modulus of wood. Taiwan Journal of Forest Science 22:297-306.

Chudnoff, M. 1980. Tropical timbers of the world. U.S. Department of Agriculture. Forest Service, Madison.

Divós, F.; Tanaka, T. 2005. Relation between static and dynamic modulus of elasticity of wood. Acta Silvatica \& Lignaria Hungarica 1:105-110.

Grabianowski, M. 2003. Measuring acoustic properties in lumber and trees. Thesis, University of Canterbury, New Zealand.

Haines, D.W.; Leban, J.M.; Herbé, C. 1996. Determination of Young's modulus for spruce, fir and isotropic materials by the resonance flexure method with comparisons to static flexure and other dynamic methods. Wood Science and Technology 30:253-263.

Hansen, H. 2006. Acoustic studies of wood. Thesis, University of Canterbury, New Zealand.

Harris, J.M. 1989. Spiral grain and wave phenomena in wood formation. Springer-Verlag, New York.

Hassan, K.T.S.; Horáček, P.; Tippner, J. 2013. Evaluation of stiffness and strength of Scots pine wood using resonance frequency and ultrasonic techniques. Bioresources 8:1634-1645.

Hein, P.R.G.; Lima, J.T. 2012. Relationship between microfibril angle, modulus of elasticity and compressive strength in Eucalyptus wood. Maderas Ciencia y Tecnología 14:267-274.

Hein, P.R.G.; Silva, J.R.M.; Brancheriau, L. 2013. Correlations among microfibril angle, density, modulus of elasticity, modulus of rupture and shrinkage in 6-year-old Eucalyptus urophylla $\times$ E. grandi. Maderas. Ciencia y Tecnología 15:171-182.

Ilic, J. 2001. Relationship among the dynamic and static elastic properties of air dry Eucalyptus delegatensis R. Baker. Holz als Roh und Werkstoff 59:169-175. 
Izekor, D.N.; Fuwape, J.A.; Oluyege, A.O. 2010. Effects of density on variations in the mechanical properties of plantation grown Tectona grandis wood. Archives of Applied Science Research 2:113-120.

Karlinasari, L.; Surjokusumo, S.; Hadi, Y.S.; Nugroho, N. 2005. Non-destructive testing on six tropical woods using ultrasonic method. In: Dwianto W (ed) Towards ecology and economy harmonization of tropical forest resources. Proceedings of the $6^{\text {th }}$ international wood science symposium. Bali, Indonesia.

Karlinasari, L.; Wabyuna, M.E.; Nugroho, N. 2008. Non-destructive ultrasonic testing method for determining bending strength properties of Gmelina wood (Gmelina arborea). Journal of Tropical Forest Science 20:99-104.

Kasal, B.; Anthony, R.W. 2004. Advances in in situ evaluation of timber structures. Progress in Structural Engineering and Materials 6:94-103.

Kolsky, H. 1963. Stress waves in solids. Dover, New York.

Kribs, D.A. 1950. Commercial foreign woods on the American market, a manual to their structure, identification, uses and distribution. Tropical Wood Laboratory, State College, PA.

Liu, Z.; Liu, Y.; Yu, H.; Juan, J. 2006. Measurement of the dynamic modulus of elasticity of wood panels. Frontiers of Forestry in China 1:245-430.

Mattheck, C.G.; Bethge, K.A. 1993. Detection of decay in trees with the metriguard stress wave timer. Journal of Arboriculture 19:374-378.

Oja, J.; Källsner, B.; Grundberg, S. 2005. Predicting the strength of sawn wood products: A comparison between $\mathrm{x}$-ray scanning of logs and machine strength grading of lumber. Forest Products Journal 55:55-60.

Oliveira, F.G.R. De; Campos, J.A.O. De; Sales, A. 2002. Ultrasound measurements in Brazilian hardwood. Materials Research 5:51-55.

Ravenshorst, G.J.P.; Van De Kuilen, J.W.G.; Brunetti, M.; Crivellaro, A. 2008. Species independent machine stress grading of hardwoods. In: Proceedings $10^{\text {th }}$ world conference on timber engineering WCTE. Miyazaki, Japan.

Ross, J.R.; Brashaw, K.B.; Wang, X.; White, H.R.; Pellerin, F.R. 2004. Wood and Timber Condition Assessment Manual. Forest Products Society, Madison.

Schajer, G.S. 2001. Lumber strength grading using x-ray scanning. Forest Products Journal 51:43-50.

Teles, R.F.; Del Menezzi, C.S.; Souza, F.; Souza, M.R. 2011. Nondestructive evaluation of a tropical hardwood: interrelationship between methods and physical-acoustical variables. Ciência da Madeira 2:1-14.

Tsoumis, G. 1991. Science and technology of wood: Structure, properties, utilization. Chapman \& Hall, New York.

Walker, J.C.F. 1993. Primary wood processing: principles and practice. Chapman \& Hall, London.

Walker, J.C.F.; Butterfield, B.G. 1996. The importance of the microfibril angle for the processing industries. New Zealand Forestry 40:34-40. 
Wang, X.; Ross, R.J.; Brashaw, B.K.; Verhey, S.A.; Forsman, J.W.; Erickson, J.R. 2003. Flexural properties of laminated veneer lumber manufactured from ultrasonically rated red maple veneer: a pilot study. Res. Note FPL-RN-0288 Forest Products Laboratory, Madison.

Weddell, E. 1961. Influence of interlocked grain on the bending strength of timber, with particular reference to utile and greenheart. Journal of the Institute of Wood Science 7:56-72.

Yang, J.L.; Evans, R. 2003. Prediction of MOE of eucalypt wood from microfibril angle and density. Holz als Roh und Werkstoff 61:449-452.

Yang, J.L.; Ilic, Y.; Wardlaw, T. 2003. Relationships between static and dynamic modulus of elasticity for a mixture of clear and decayed eucalypt wood. Australian Forestry 66:193-196.

Zhou, Z.R.; Zhao, M.C.; Wang, Z.; Wang, B.J.; Guan, X. 2013. Acoustic testing and sorting of Chinese poplar logs for structural LVL products. Bioresources 8:4101-4116.

Zobel, B.J.; Van Buijtenen, J.P. 1989. Wood Variation: Its Causes and Control. Springer Verlag, Berlin. 